\title{
The Arabs' scientific vision
}

\author{
Winds of change blow through research centres and universities operating in the Middle East.
}

The Canon of Medicine by Ibn Sina (Avicenna in Latin), the studies on algebra and arithmetic of Al-Khwārizmī (Algoritmi), the Book of Optics by Ibn al-Haytham (Alhazen): these are just a few examples of Middle Eastern literature from the past that testify the outstanding contribution of Islamic intellect to modern science. However, statistics on the scientific impact of today's Arab world portray a starkly different picture, with universities and research centres from these countries lagging well behind their Eastern Asiatic and Western counterparts ${ }^{1,2}$. The output of publications from the entire Middle Eastern region in 2012 amounts to less than one quarter of that of the US ${ }^{1}$, and only three universities (two from Israel and one from Turkey) are listed in the top 200 institutions in teaching and research worldwide ${ }^{2}$. Yet, an awakened community is now eager to trigger a scientific rebirth in this area.

As the 1999 Nobel Laureate in Chemistry, Ahmed Zewail, discusses in a Commentary on page 318 of this issue, drastic reform is essential after decades of ineffective education policies, low literacy levels and suppression of free thinking. A young population striving for an active role in society - as demonstrated during the recent events of the Arab Spring - is the principal component required for a deep scientific and cultural transformation. Also, the abundance of natural resources and, for some countries at least, a wealthy economy, can provide the necessary support for developing a more efficient education and research infrastructure.

The necessity to move towards a knowledge-driven society is now permeating the Middle East, and some countries are heavily financing this challenging transition. For example, a centre of excellence for higher education and research, the Zewail City of Science and Technology, has been created in Egypt thanks to donations from its people and Government. The King Abdullah University of Science and Technology (KAUST) in Saudi Arabia aims to become a world-leading research centre operating in areas such as solar energy, water desalination, catalysis and combustion. The vice-president for research at KAUST, Jean M. J. Fréchet, mentions in an Interview on page 321 the generous funding that scientists working at KAUST

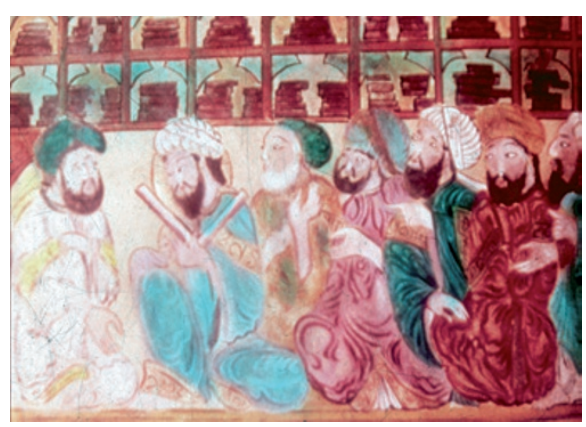

Students in the House of Wisdom in Baghdad, during the Islamic Golden Age. (c) Image Asset Management Ltd/Alamy.

receive as a support for their research, mainly coming from donations - which amount to more than US\$10 billion - from the Saudi Kingdom. Also Qatar has planned an increase in the national expenditure on research and development, to reach $2.8 \%$ of their gross domestic product in the next few years ${ }^{3}$. Thomas Zacharia, the vice-president of research and development of the Qatar Foundation, explains in an Interview with Nature Middle East - an online portal of scientific and medical research in the Arabic-speaking Middle East - the strategies they will adopt to focus both the country's resources and ongoing research on three main challenges for Qatar ${ }^{3}$ : water security, energy security and cyber security.

Beyond the commitment of financial support, equally important for the success of these centres is the recognition of their full scientific independence from central governments, and thus the protection of scientific inquiry and debate from political or religious interferences. This has been established in statutory laws for Zewail City as well as for the international board of trustees managing KAUST in Saudi Arabia. The privileged position of the latter university is manifest in the campus lifestyle it fosters, where equal opportunities are granted with no sexual or religious discrimination.

These centres of excellence have already attracted a large number of scientists from abroad. Enzo Di Fabrizio, an Italian professor who recently relocated to Saudi Arabia, talked to Nature Middle East about the excellent funding opportunities - in striking contrast with
US and European austerity policies - and the open-minded and cooperative research environment found at KAUST ${ }^{4}$. In a similar vein, other researchers who have jumped at the opportunities opened by these new realities in the Gulf region do not regret the move $e^{5,6}$

Local and international scientists also look to nurture a research mentality in the local population by transferring their knowledge to undergraduate and graduate students. To comply with this educational mission, most research centres have specific projects dedicated to talented Arab students, who are either enrolled in international study programmes abroad or offered advanced academic curricula in local universities. After graduation, these students can now choose among an increasing number of $\mathrm{PhD}$ programmes tutored by international researchers directly in the region, and have post-doctoral positions available in their home countries that offer them opportunities to develop their research further and compete for faculty positions around the world.

The creation of scientific hubs able to both play a relevant role in the international community and involve an increasing number of Arab students in research may catalyse the change needed in the Middle East. Certainly, it will be interesting to observe the effects of these efforts on the scientific productivity of the next few years. In the long term, one only hopes that the exposure of young generations to a multicultural, curiosity-driven research environment will spark a new scientific golden age in the region.

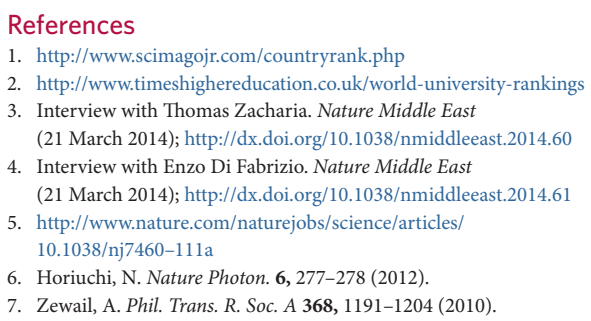

\section{Correction}

In the version of the Editorial 'Consider Luxembourg' originally published (Nature Mater. 13, 215; 2014), the image of Luxembourg town hall was wrong. Corrected in the PDF and HTML versions after print 20 February 2014. 